\title{
Probable maximum precipitation 24 hours estimation: A case study of Zanjan province of Iran
}

\author{
Azim Shirdeli*
}

Department of Civil Engineering, Zanjan University Zanjan, Iran

\begin{tabular}{l}
\hline A R T I C L E I N F O \\
\hline Article history: \\
Received March 15, 2012 \\
Received in Revised form \\
March, 15, 2012 \\
Accepted 16 May 2012 \\
Available online \\
May 18 2012 \\
\hline Keywords: \\
Probable maximum precipitation \\
PMP \\
Civil structures \\
Maximum Likelihood
\end{tabular}

\section{Introduction}

One of the most important issues in designing flood control dams upstream of populated areas and reservoirs is to determine the largest flood possible at a location to maintain the maximum reliability and safety of the local residence (Maidment, 1992). There are literally many examples where a bad design perspective caused catastrophic incidents such as Fukushima earthquake. There are many cases where the risk of dam overtopping is deemed unacceptable and an estimate of the probable maximum precipitation (PMP) depth can be used to find the probable maximum flood (PMF) for that location. PMP is the conceptual construct, which defines the magnitude of extreme storms implemented in the design of dams and reservoirs and it has been become a popular method among practitioners (Ellen et al., 2002). According to Hansen et al. (1982), the PMP is defined as the "theoretically greatest depth of precipitation for a given duration that is physically possible over a given size storm area at a particular geographical location at a certain time of the year’’ 
There are literally tremendous efforts on contributing dams' design using PMP methods during the past few years. Rezacova et al. (2005) explained the necessity of using new techniques for estimating floods for reservoir outflow structure s in the Czech Republic (CR) based on undesirable incidents happened in the Odra flood in Central Europe in 1997. They aimed to use some statistical data of the point and area PMP estimates for precipitation duration of 1 to 5 days. The use of radar data in evaluating the maximized area reduction factor was explained and the relationship resulting from the radar measurements over the CR territory was outlined. They reported the results obtained by comparing the rainfalls in 1997 and 2002 flood events with the PMP estimates. The comparison demonstrated that the maximum area rainfalls over small Czech catchments had not exceed 63\% of the corresponding PMP values.

Carmen Casas et al. (2010) estimated PMP in Barcelona from 5 minutes to 30 hours. They used two various techniques and compared, where the first one was associated with a physical method based on the maximization of actual storms, and the Hershfield' statistical method (Hershfield, 1961, 1965; Chow et al., 1988). The PMP results calculated based on two techniques were very similar and for both cases. Desa M et al. (2001) explained PMP for stations in Malaysia using Hershfield method as mean plus 15 standard deviations processed from yearly maximum rainfall information. The data of 15 as frequency factor was too high for a humid region such as Malaysia. Desa M et al. (2001) in their work used yearly maximum 1-day rainfall data of about 30-60 years for 33 stations in the region of Selangor, Malaysia and estimated PMP for 1-day duration based on a suitable frequency factor. The PMP map was reported as an important method to determine reliable and consistent PMP estimate for any location in Selangor, Malaysia, for designing relatively expensive hydraulic structures. Tingsanchali and Tanmanee (2012) performed the hydrological assessment by estimating the PMP over Mae Sruai River Basin using two techniques, where the first PMP method is based on statistical approach while the second one is based on storm maximization and transposition approach to calculate the 1-day, 2-day and 3-day PMPs.

In this paper, we present an implementation of PMP method to predict precipitation in city of Zanjan, Iran. The organization of this paper first explains the proposed method in section 2 and details of findings are given in section 3. The paper ends with concluding remarks to summarize the contribution of the paper.

\section{The proposed model}

There different ranges for PMP and a 24-hour scale is shown as $\mathrm{PMP}_{24}$ and it is calculated as follows,

$$
x_{t}=\overline{x_{n}}+K \sigma_{n} \text {, }
$$

where $x_{t}$ is the precipitation height for back period $\tau, \bar{x}_{n}$ and $\sigma_{n}$ are the average and standard deviation of $x_{t}$, respectively. In addition, $v$ is the number of precipitation and $K$ is the frequency. Let $m$ be the subscript representing the maximum amount of $x$ and K. Therefore, we have,

$$
P M P=\bar{x}_{n}+K_{m} \sigma_{n}
$$

In order to calculate PMP, we use the following three techniques.

\subsection{First Hershfield method}

This is the official method recommended by many governmental organization to calculate PMP and it is as follows,

1. Calculate $K_{m}$ 
2. Remove the maximum value from the data and calculate $\bar{x}_{n-m}$ and $\sigma_{n-m}$,

3. Calculated adjusted value for $\bar{x}_{n}$ and $\sigma_{n}$ based on $\bar{x}_{n}, \sigma_{n}, \bar{x}_{n-m}$ and $\sigma_{n-m}$,

4. Based on the statistical time horizon calculate imply corrected coefficients into $\bar{x}_{n}$ and $\sigma_{n}$,

5. Calculate PMP

\subsection{The Second method: An extended Hershfield method}

In the second method, we do our calculation without considering the maximum precipitation as follows,

$$
K_{m}=\left(X_{m}-\bar{X}_{n-m}\right) / \sigma_{n-L}
$$

where $x_{m}$ is the maximum precipitation, $\bar{x}_{n-m}$ and $\sigma_{n-m}$ are the average and standard deviation of the data after removing the maximum precipitation.

There is also another technique where we define lower and upper limits for the data. Then we remove any data located outside the limits (The third method).

\section{Case study}

Zanjan has an area of 22,164 $\mathrm{km}^{2}$, occupying $1.34 \%$ of the Iranian territory, the average population density in Zanjan is $4 \frac{1}{4}$ people per $\mathrm{km}$ and it is located on north-west of Iran. The average precipitation is about $323 \mathrm{~mm}$ and the number of snow days is 115 days. There are 13 stations located in this province, which calculates precipitation for, at least, 17 years.

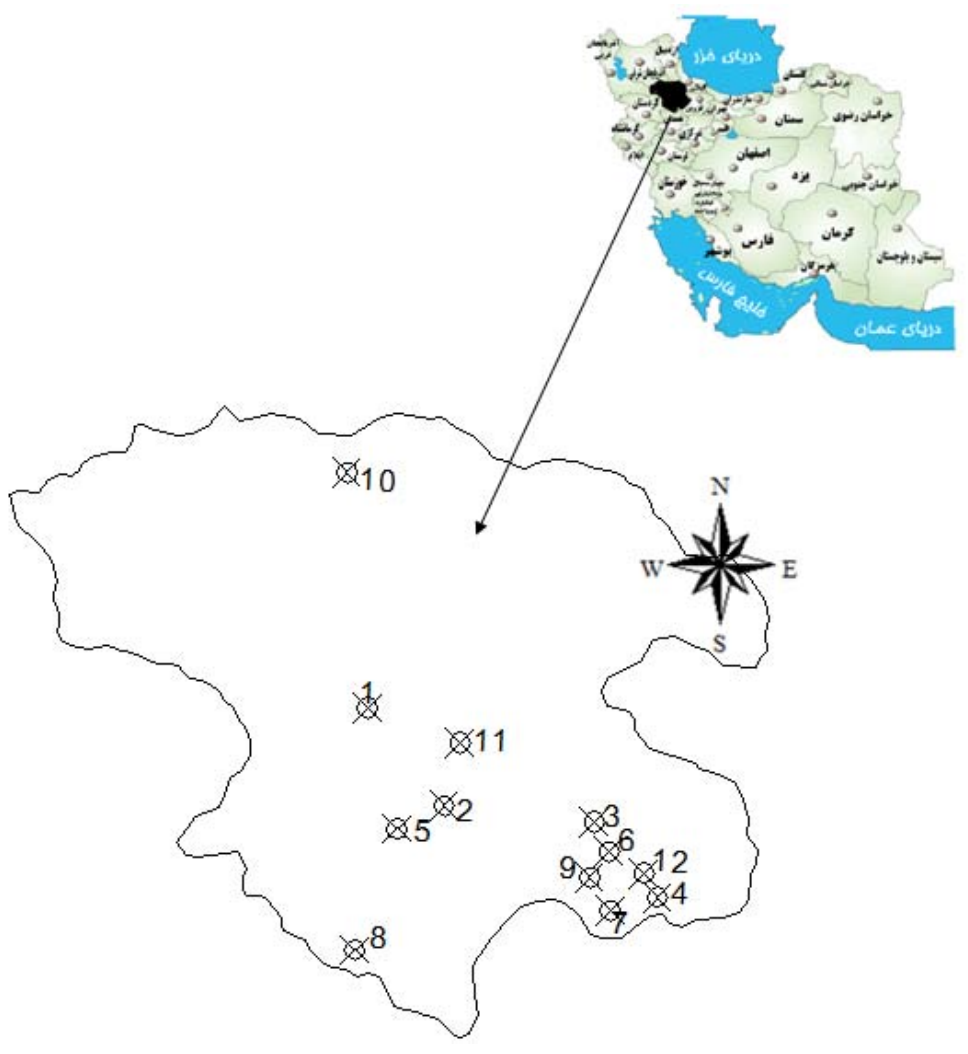

Fig. 1 Different stations in province of Zanjan 
Table 1 shows details of these stations.

\section{Table 1}

Characteristics of different stations in province of Zanjan

\begin{tabular}{ccccc}
\hline Station & Period (year) & Altitude & Latitude & Longitude \\
\hline 1 & 50 & 1663 & $36-41$ & $48-29$ \\
2 & 36 & 1780 & $36-26$ & $48-47$ \\
3 & 35 & 2020 & $36-25$ & $49-02$ \\
4 & 35 & 1433 & $36-03$ & $49-22$ \\
5 & 35 & 1850 & $36-08$ & $48-45$ \\
6 & 33 & 1693 & $36-18$ & $49-04$ \\
7 & 31 & 1910 & $36-00$ & $49-05$ \\
8 & 31 & 1830 & $35-48$ & $48-41$ \\
9 & 31 & 1819 & $36-09$ & $49-03$ \\
10 & 30 & 1750 & $37-06$ & $48-11$ \\
11 & 29 & 2028 & $36-18$ & $48-54$ \\
12 & 24 & 1575 & $36-11$ & $49-11$ \\
\hline
\end{tabular}

In order to examine whether the data are equally distributed we use the following,

$$
\begin{gathered}
\tau=\frac{4 \sum n_{i}}{n(n-1)}-1, \\
\sigma_{\tau}=\sqrt{\frac{4 n+10}{9 n(n-1)},}
\end{gathered}
$$

where $\tau$ is the Kendall ratio and $\sigma_{\tau}$ is the standard deviation of Kendall ratio. Table 2 shows the ratios of $\tau / \sigma_{\tau}$ for all stations,

Table 2

The summary of $\tau / \sigma_{\tau}$ for 13 stations

\begin{tabular}{cccccccccccccc}
\hline Station & 1 & 2 & 3 & 4 & 5 & 6 & 7 & 8 & 9 & 10 & 11 & 12 & 13 \\
\hline $\mathrm{n}$ & 50 & 41 & 37 & 36 & 37 & 35 & 33 & 33 & 31 & 30 & 31 & 24 & 17 \\
$\tau / \sigma_{\tau}$ & -6.23 & -6.58 & -3.19 & -4.87 & -3.79 & -2.93 & -3.22 & -3.87 & -4.74 & -3.26 & -2.70 & -0.89 & -0.33 \\
\hline
\end{tabular}

Based on the calculations given in Table 2, the data for station 12 and station 13 were not suitable and therefore we set them aside for the next step. Table 3 shows details of our computations for three proposed methods explained earlier.

\section{Table 3}

The summary of PPM method using three different methods

\begin{tabular}{llllllllllll}
\hline Station & 1 & 2 & 3 & 4 & 5 & 6 & 7 & 8 & 9 & 10 & 11 \\
\hline First method & 202.74 & 229.55 & 230.26 & 170.14 & 205.43 & 199.00 & 192.43 & 187.15 & 215.09 & 205.92 & 255.28 \\
Second method & 76.12 & 83.90 & 91.13 & 62.33 & 72.74 & 73.15 & 71.20 & 73.30 & 80.72 & 79.90 & 92.08 \\
Third method & 97.96 & 110.26 & 95.17 & 76.08 & 85.15 & 95.99 & 93.31 & 76.57 & 99.48 & 87.89 & 117.28 \\
\hline
\end{tabular}

Fig. 1 demonstrates the precipitation rates for the implementation of the third method. 

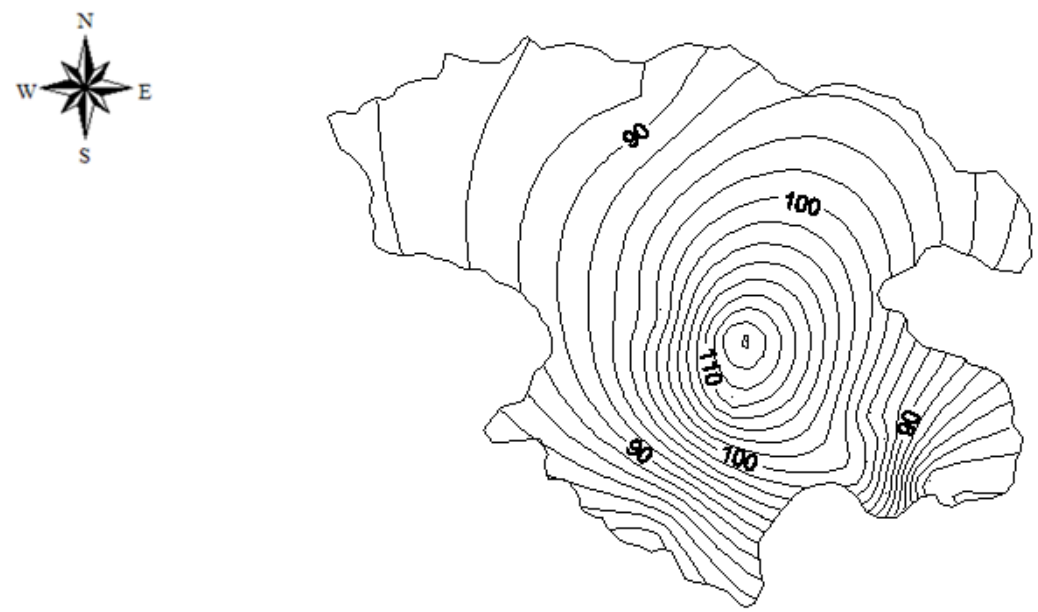

Fig. 1. Precipitation rate for the third method

As we can observe from the information of the Fig. 1, the maximum precipitation rate is located near the center of province while the maximum rate of precipitation rate is on the corner sides of the province.

\section{Conclusion}

In this paper, we have explained the relative importance of designing civil structures such as water storage dams and irrigation and drainage networks based on economic scale using the possibility of natural incidents such as floods, earthquake, etc. The proposed model of this paper used probable maximum precipitation to calculate the maximum precipitation. We have used three methods, based on Hershfield methods, which implement the maximum one-day precipitation using 17 to 50 years of information in 13 stations located in province of Zanjan, Iran. The results of the first model yielded 18.17 to 18.48 for precipitation where the PMP24 was between $170.14 \mathrm{~mm}$ and $255.28 \mathrm{~mm}$. The results of the second method reported precipitation between 2.29 and 4.95 while PMP24 was between $62.33 \mathrm{~mm}$ and $92.08 \mathrm{~mm}$. In addition, when the out of range data were deleted from the study of the second method, precipitation rates were calculated between 2.29 and 4.31 while PMP24 was between $76.08 \mathrm{~mm}$ and $117.28 \mathrm{~mm}$. The preliminary results have indicated that the second Hershfield method provide more stable results than the first one.

\section{Acknowledgment}

The authors would like to thank the anonymous referees for constructive comments on earlier version of this paper.

\section{References}

Chow, V. T., Maidment, D. R., \& Mays, L. W. (1988). Applied Hydrology, McGraw-Hill, USA

Desa M, M.N., Noriah, A.B., \& Rakhecha, P.R. Probable maximum precipitation for $24 \mathrm{~h}$ duration over southeast Asian monsoon region-Selangor, Malaysia. Atmospheric Research, 58(1), 41-54.

Eliason, J. (1997). A statistical model for extreme precipitation. Water Resources Research,33(3), 449-455.

Gahraman, B. (2007). The estimation of one day duration probable precipitation over Atrak watershed in Iran. Iranian Journal of Science and Technology, 32, 175-179. 
Hansen, E. M., L. C. Schreiner, \& Miller, J. F. (1982). Application of probable maximum precipitation estimates, United States east of the 105th meridian. Hydrometeorological Rep. 52, National Weather Service, Silver Spring, MD, 176.

Hershfield, D. M. (1961). Estimating the probable maximum precipitation. Journal of Hydraulic Engineering, 87, 99-106.

Hershfield, D.M. (1965) Method for estimating probable maximum precipitation.

Journal of American Water Works Association, 57, 965-972.

Koutsoyainnis, D. (1999). A probabilistic view of Hershfield's method for estimating probable maximum precipitation”, water Resource, Res.

Maidment, D.R. (1992). Handbook of Hydrology. McGraw-Hill, USA.

Rezacova, D., Pesice, P., \& Sokol, Z. (2005). An estimation of the probable maximum precipitation for river basins in the Czech Republic. Atmospheric Research, 77(1-4), 407-421.

Tingsanchali, T., Tanmanee, S. (2012). Assessment of hydrological safety of Mae Sruai Dam, Thailand. Procedia Engineering, 32, 1198-1204

World meteorological Organization (WMO) (1986). Manual for Estimation of Probable Maximum Precipitation: summary. 2nd,WMO 332, 1. 